\title{
Transanular Interaction in [2.2]Phanes: [2.2](2,7)Pyrenophane
}

\author{
D. Schweitzer, K. H. Hausser, R. G. H. Kirrstetter, and H. A. Staab \\ Max.Planck-Institute, Department of Molecular Physics, Department of Organic Chemistry, \\ Heidelberg
}

(Z. Naturforsch. 31 a, 1189-1192 [1976]; received August 26, 1976)

\begin{abstract}
The emission spectra of [2.2] $(2,7)$ pyrenophane and the zero field splitting parameters $D$ und $E$ of its excited triplet state were measured in glasses and in small single crystals at $1.3 \mathrm{~K}$. The results are being compared with monomer pyrene and 2,7-dimethylpyrene in liquid and solid solutions as well as in single crystals.
\end{abstract}

\section{Introduction}

The investigation of [2.2] phanes provides information on the transanular intramolecular $\pi$-electron interaction through space. In two preceding papers $^{1,2}$ we have studied a number of isomers of naphthalenophanes as well as biphenylophane and phenanthrenophane. Methods used were emission spectroscopy at low temperatures $(1.3-4.2 \mathrm{~K})$ and the measurement of the triplet zero field splitting parameters $D$ and $E$ by optical detection of magnetic resonance (ODMR) both in glass matrices and in some cases in single crystals. The results are relevant for the understanding of similar intermolecular interactions in excimers and exciplexes.

The phenomenon of excimer formation was first discovered with the example of pyrene in solution by Förster and Kasper ${ }^{3}$. Later on an excimer fluo. rescence was also observed in a pyrene single crys$\operatorname{tal}^{4,5}$. Hence it seemed to be of particular interest to extend the investigations of the [2.2] phanes to [2.2] $(2,7)$ pyrenophane $(1)$ which has recently been synthesized ${ }^{6}$ and to compare the results with pyrene (2) and 2,7-dimethylpyrene (3) and with the excimers in solution and in single crystals.

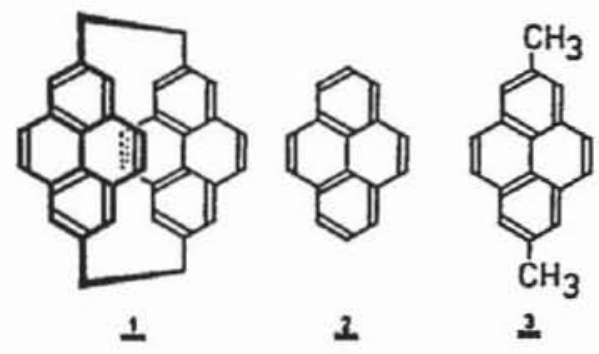

\section{Results}

We report here on the fluorescence and phosphorescence spectra as well as on the $D$ and $E$ parame- ter of pyrene 2, dimethylpyrene 3 and pyrenophane 1 measured in small single crystals and in glasses and solutions of 2-methyltetrahydrofuran (MTHF). The experimental set-up used to record the luminescence and the ODMR spectra was similar to the one described by Zuclich et al. ${ }^{7}$ equipped with the photomultiplier RCA $31034 \mathrm{~A} 02$ for recording the long wavelength spectra. The measurements were performed at $1.3 \mathrm{~K}$.

The fluorescence and phosphorescence spectra are shown in the Figure: The emission spectra of pyrene 2 (a) and dimethylpyrene 3 (c), concentration $5 \cdot 10^{-3} \mathrm{~mol}$, in a rigid glass of MTHF at $1.3 \mathrm{~K}$ are typical monomer spectra; they exhibit the wellknown excimer fluorescence ${ }^{3}$ after melting at room temperature (b and d). The fluorescence spectra of single crystals of pyrene 2 and dimethylpyrene $\mathbf{3}$ differ considerably. The broad fluorescence band (f) of pyrene single crystals ${ }^{5}$ which consists of pairs of pyrene molecules occurs at almost the same wave number as the excimer in solution (b), in contrast to the fluorescence of small single crystals of dimethylpyrene 3 (e) the red shift of which with respects to the monomer is much smaller. The fluorescence spectra of $[2.2](2,7)$ pyrenophane $(1)$ in the rigid glass of MTHF (g) and in small single crystals (h) are broad and structureless as well, but they are shifted considerably farther to the red than in the case of the pyrene crystal. Inspite of the large shift of the fluorescence the phosphorescence is only very little shifted to the red. The phosphorescence of the pyrenophane 1 exhibits essentially the same although somewhat broadened structure as the phosphorescence of the monomers. For quantitative comparison, the wave numbers of the fluorescence and of the phosphorescence are compiled in the Table together with the zero field splitting parameters $D$ and $E$. 


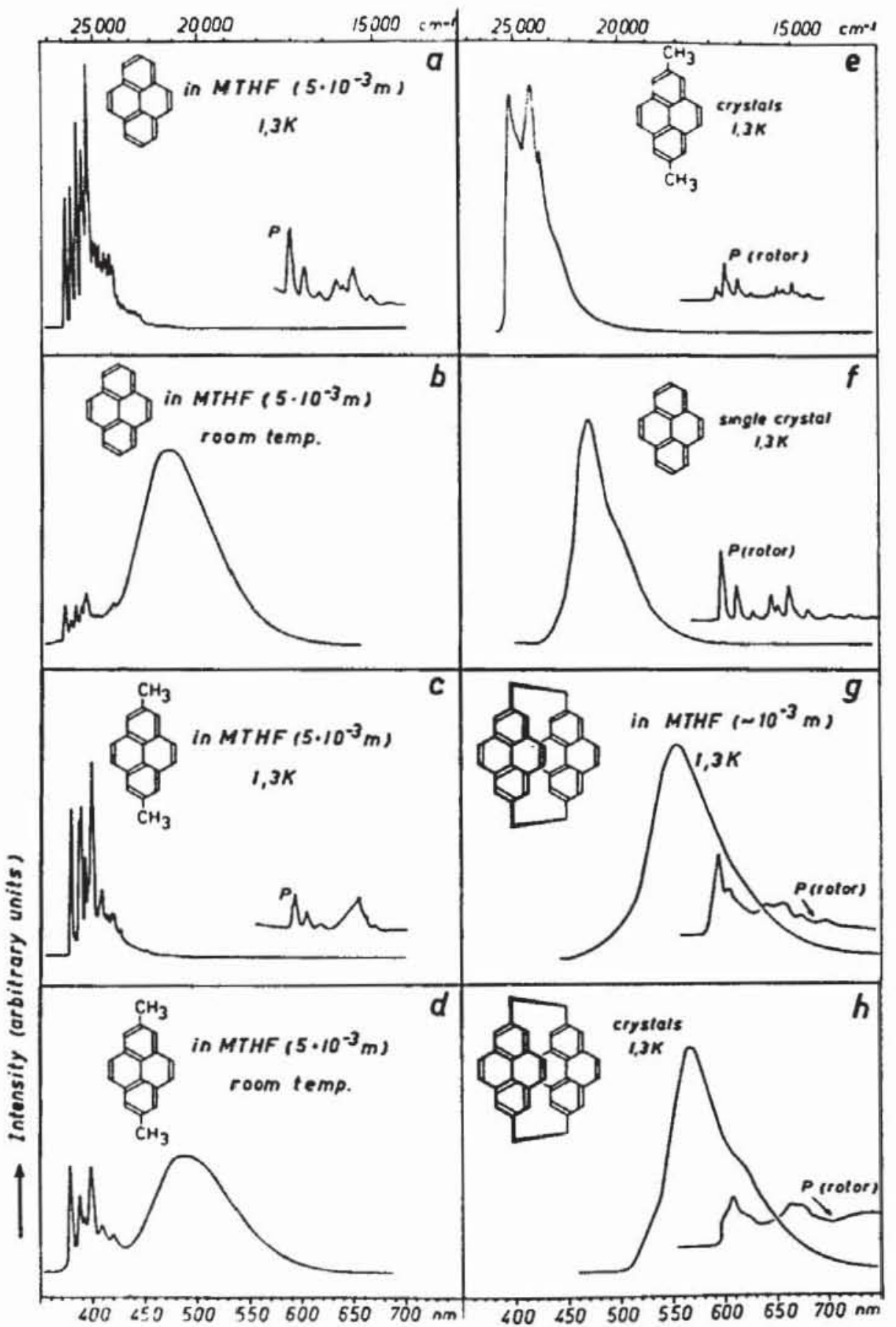

Fig. 1.

Left:

Emission spectra of pyrene (2) and 2,7-dimethylpyrene (3) in 2-methyltetrahydrofuran (MTHF) at $1.3 \mathrm{~K}$ (a and $\mathrm{c}$ ) and at room temperature (b and d). Right:

Emission spectra of $\mathbf{2}$ and $\mathbf{3}$ in single crystals ( $e$ and $f$ ) and of $[2.2](2,7)$ pyrenophane (1) in MTHF (g) and in single crystals (h) at $1.3 \mathrm{~K}$. $P$ indicates phosphorescence, and was taken with higher amplification than the total emission spectra.

\section{Discussion}

In previous papers 1,2 we have compared the phanes with the dimethyl substituted monomers. An analogous comparison of the pyrenophane $\mathbf{l}$ with the dimethylpyrene 3 is appropriate when dealing with liquid and solid solutions in MTHF, but single crystals of dimethylpyrene 3 are not appropriate for comparison. While the red shift of the fluorescence of pyrene $\mathbf{2}$ in solution at room temperature (b) is almost identical with the one observed in single crystals, i.e. about $5000 \mathrm{~cm}^{-1}$, the much smaller red shift in crystalline dimethylpyrene 3 of $1450 \mathrm{~cm}^{-1}$ indicates a considerably weaker $\pi$-electron interaction. Since the crystal structure of dimethylpyrene 3 is not known, it remains open whether it does not crystallize in a type B lattice with two molecules forming a pair like pyrene ${ }^{\mathbf{8}} \mathbf{2}$ or whether the crystal structure is similar to pyrene $\mathbf{2}$, but the planes are kept farther apart because of the steric hinderance of the methyl groups.

The fluorescence band of the pyrenophane 1, on the other hand, is shifted still considerably farther 
Table 1. Wave numbers of the $0-0$-transitions $v_{0-0}$ and of the centers of the broad excimer bands $\nu_{\max }$ of the fluorescence and of the phosphorescence as well as the zero field splitting parameters $|D|$ and $|E|$ of the $[2.2](2,7)$ pyrenophane (1), pyrene (2) and 2,7-dimethylpyrene (3) in 2-methyltetrahydrofuran (MTHF) and in single crystals.

\begin{tabular}{|c|c|c|c|c|c|c|c|c|}
\hline & \multirow{2}{*}{$\begin{array}{l}\text { Temp. } \\
{[\mathrm{K}]}\end{array}$} & \multicolumn{3}{|c|}{ Fluorescence $\left[\mathrm{cm}^{-1}\right]$} & \multicolumn{2}{|c|}{ Phosphorescense $\left[\mathrm{cm}^{-1}\right]$} & \multirow{2}{*}{$\begin{array}{l}|D| \\
{\left[\mathrm{cm}^{-1}\right]}\end{array}$} & \multirow{2}{*}{$\begin{array}{l}|E| \\
{\left[\mathrm{cm}^{-1}\right]}\end{array}$} \\
\hline & & $v_{0-0}$ & $v_{\max }$ & $v_{\max , \operatorname{mon}}-v_{\max }$ & $y_{0}-0$ & $\nu_{0}-0$, mon $-\nu_{0-0}$ & & \\
\hline $\begin{array}{l}\text { Pyrene } 2 \text { in } \\
\text { MTHF }\end{array}$ & 1.3 & 26900 & 26150 & & 17020 & & 0.0859 & 0.0168 \\
\hline $\begin{array}{l}\text { Dimethylpyrene } 3 \\
\text { in MITHF }\end{array}$ & 1.3 & 26400 & 25850 & & 16935 & & 0.0855 & 0.0169 \\
\hline $\begin{array}{l}\text { Pyrene } 2 \text { in } \\
\text { MTHF }\end{array}$ & r.t. & & 21100 & 5050 & & & & \\
\hline $\begin{array}{l}\text { Dimethylpyrene } 3 \\
\text { in MTHF }\end{array}$ & r.t. & & 20400 & 5450 & & & & \\
\hline $\begin{array}{l}\text { Pyrene } 2 \\
\text { Single Crystal }\end{array}$ & 1.3 & & 21200 & 4950 & 16690 & 330 & 0.0835 & 0.0157 \\
\hline $\begin{array}{l}\text { Dimethylpyrene } 3 \\
\text { Single Crystals }\end{array}$ & 1.3 & 25200 & 24400 & 1450 & 16835 & 100 & 0.0818 & 0.0162 \\
\hline $\begin{array}{l}\text { Pyrenophane } 1 \\
\text { in MTHF }\end{array}$ & 1.3 & & 18000 & 7850 & 16785 & 150 & 0.0834 & 0.0166 \\
\hline $\begin{array}{l}\text { Pyrenophane } 1 \\
\text { Crystalline }\end{array}$ & 1.3 & & 17600 & 8250 & 16690 & 330 & 0.0790 & 0.0160 \\
\hline
\end{tabular}

to the red $\left(7850 \mathrm{~cm}^{-1}\right)$ indicating an even stronger interaction between the two $\pi$-electron systems. This result is at least qualitatively plausible if one takes into account that the distance between two pyrene molecules forming a pair in a crystal is $3.53 \AA$ which is reduced in the excimer following calculations of Birks and Kazzaz ${ }^{5}$ by about two tens of an $\AA$, while the distance in the pyrenophane $\mathbf{1}$ is certainly not more than $3 \AA$ in the average *.

The pyrene crystal is known to emit only excimer fluorescence and phosphorescence typical for monomers ${ }^{10}$. It was concluded that in the triplet state it does not form excimers ${ }^{10}$ but has about the same distance like the ground state ${ }^{11}$. However, although the phosphorescence shows sharp vibrational structure, its red shift is not zero but $330 \mathrm{~cm}^{-1}$ for pyrene 2 and $100 \mathrm{~cm}^{-1}$ for dimethylpyrene 3 with respect to the monomers. The ratio of the shifts of the fluorescence to the phosphorescence are very similar, i. e. about 15 both for 2 and 3.

The most striking observation of the phosphorescence of the pyrenophane $\mathbf{1}$ in MTHF is that inspite of the much closer distance it shows a similar although somewhat broadened structure and a red

- The X-ray structure analysis of pyrenophane $\mathbf{I}$ is not yet completed, but as known in the case of the [2.2]paracyclophane ${ }^{2}$ the aromatic nuclei are deformed into a boat conformation resulting in a distance of about $2.8 \AA$ close to the $-\mathrm{CH}_{2}-\mathrm{CH}_{2}$-bridges and of about $3.1 \AA$ in the middle. shift of $150 \mathrm{~cm}^{-1}$ with respect to 3 which is only about one half of the shift in the pyrene crystal.

The zero field splitting parameter $D$ is found to be identical for crystalline pyrene and for pyrenophane 1 in MTHF and only $3 \%$ smaller than for the monomers 2 and $\mathbf{3}$ the $D$ values of which are very similar. For small single crystals of the pyrenophane 1 , on the other hand, the $D$ value is reduced by about $8 \%$ with respect to the monomers.

A somewhat weaker coupling between the two sub-units of a phane in a triplet state as compared to the singlet state was interpreted previously ${ }^{1}$ in terms of a smaller spatial extension of the triplet orbital than the one of the singlet orbital in analogy to the results obtained with smaller systems.

The importance of the exciton resonance and the charge resonance for the energy of the excimer state was also emphasized ${ }^{11}$ and it was pointed out that these interactions might reduce the energy of the triplet excimer state less than the one of the singlet excimer state ${ }^{11}$. However, it remains surprising that both the red shift of the phosphorescence and the $D$ value are almost identical for crystalline pyrene $\mathbf{2}$ and for pyrenophane $\mathbf{1}$ and differ very little from monomere pyrene inspite of the rather large difference in the distance between the relevant $\pi$-electron systems. The theoretical aspects of these experimental findings will be discussed in a subsequent paper together with additional experimental results. 
1 D. Schweitzer, J. P. Colpa, J. Behnke, K. H. Hausser, M. Haenel, and H. A. Staab, Chem. Phys. 11, 373 [1975].

2 D. Schweitzer, J. P. Colpa, K. H. Hausser, M. Haenel, and H. A. Staab, J. Luminescence 12/13, 363 [1976].

3 Th. Förster and K. Kasper, Z. Physik. Chem. (Frankfurt) NF 1, 275 [1954] ; Z. Elektrochem. 59, 976 [1955].

- B. Stevens, Spectrochim. Acta 18, 439 [1962].

5 J. B. Birks and A. A. Kazzaz, Proc. Roy. Soc. London A 304, 291 [1968].

- R. G. H. Kirrstetter and H. A. Staab, to be published. - See also: T. Umemoto, S. Satani, Y. Sakata, and S. Misumi, Tetrahedron Lett. 1975, 3159;R. H. Mitchell, R.
J. Carruthers, and J. C. M. Zwinkels, Tetrahedron Lett. 1976, 2585.

7 J. Zuclich, D. Schweitzer, and A. H. Maki, Photochem. Photobiol. 18, 161 [1973].

8 A. Camerman and J. Trotter, Acta Cryst. 18, 636 [1965].

- D. K. Lonsdale, H. J. Milledge, and K. V. Krishna Rao, Proc. Roy. Soc. London A 255, 82 [1960] ; H. Hope, J. Bernstein, and K. N. Trueblood, Acta Cryst. B 28, 1733 [1972].

${ }^{10} \mathrm{~L}$. Peter and G. Vaubel, Chem. Phys. Lett. 21, 158 [1973].

11 J. B. Birks, in "The Exciplex" (M. Gordon and W. R. Ware, eds.), p. 39, Academic Press Inc., New York 1975, and literature quoted there. 